Viewpoints and Letters to the Editor are published in Hort- comments on matters of concern to horticulturists. These are Science to provide members of the American Society for Hor- not statements of official Society policy nor do they necessarticultural Science an opportunity to share their experiences and ily reflect the views of a majority of the Society's Members.

\title{
Professional Schools for Agriculture
}

\author{
Arthur Wallace \\ Complete Green Company, 365 Coral Circle, El Segundo, CA 90245
}

\begin{abstract}
Agriculture, especially in developed countries, has undergone and will continue to undergo drastic changes. Pressures are forcing more sustainability, fewer pesticides, and more environmental awareness. More efficiency and higher precision in all aspects of farm management will be needed.

Many skilled professionals will be needed in the future for the decisions and management required for a safer and more productive agriculture on a decreased land base. The type of professionals needed includes those with a generalist's point of view and the ability to handle and process data and integrate several disciplines, such as agronomy, horticulture, soil science, plant pathology, entomology, economics, computer science, agricultural engineering, and others. Basic disciplines of mathematics, chemistry, physics, botany, zoology, microbiology, and related subtopics often will be needed. Communication skills are also important. There is a special need for skills to access information. Therefore, there is a need for a new type of professional agricultural training, but the old must be retained as well for the development of specialists.
\end{abstract}

Professional schools for medicine, law, engineering, the environment, and other disciplines are well known. Agriculture could also have professional schools, since it, like other professions, combines several disciplines. Pre-ag studies for a program to result in an award of a degree of Doctor of High Precision Agriculture (DHPA) could be the equivalent of a BS degree in one of a number of disciplines, and $\mathrm{MS}$ and $\mathrm{PhD}$ candidates could also be admitted to the program. Conversely, DHPA graduates could later earn a $\mathrm{PhD}$, if desired. The core courses needed could be taken before or after beginning the program, and the time needed to complete the DHPA could vary according to prior studies. Students could even be admitted to the program after 3 years of preparation and obtain the BS degree simultaneously. A period of residence or apprenticeship on a farm or other agricultural enterprise should be expected for the DHPA degree.

The DHPA curriculum would emphasize management with systems approaches that blend with economics and engineering. Full

Received for publication 9 July 1991. The cost of publishing this paper was defrayed in part by the payment of page charges. Under postal regulations, this paper therefore must be hereby marked advertisement solely to indicate this fact. consideration for the environment and for the health of consumers would be given in the multidisciplinary approach.

DHPA graduates would be valuable in the roles of consultants, farm advisors, faculty members, laboratory professionals, agents for industry, farm owners or managers, and as members of the management staff of a $21 \mathrm{st}$ century farm. Groups of DHPAs could work together in private practice as do medical groups and law firms. A well-trained and capable DHPA can be expected to be in demand and to command compensation commensurate with professional standing. For expert management of perhaps 80 million ha of the top farm land in the United States, the nation could use as many as 40,000 DHPAs. A stable number of DHPAs at that level, each averaging 30 years of service, would require 1300 or so graduates per year at equilibrium or 5000 in 4-year schools at a time; 4000 if in 3-year schools. Twenty professional schools in the United States could handle the load, but some foreign students most likely would be added, in addition to some U.S. students who would do foreign service. As many as 6000 students may be in the program at once, with 1500 to 2000 new admissions each year.

The cost on a national basis for a program of this magnitude at the university or college level could be $\$ 40$ million/year-less than 1/ 25 of $1 \%$ of all farm income. The combined incomes of 40,000 DHPA professionals on the job sometime in the future could be $<2 \%$ of all farm income. The value can be infinitely more. Federal grants may be needed to start programs in this direction.

Colleges of agriculture already exist at many major universities where BS and often $\mathrm{MS}$ and $\mathrm{PhD}$ degrees are offered in agricultural disciplines. Much of the overhead cost, therefore, is already being paid with the existence of these colleges. Many colleges have too few students anyway; some colleges of agriculture have enrollments so low that their very existence is threatened. A DHPA program could bring back colleges of agriculture that are on the verge of extinction.

A college of agriculture could offer a DHPA program with considerable cooperation of other units on campus. The cost to establish a DHPA program need not be prohibitive; therefore, tuition need not be prohibitive. Grants to universities for the program could come from the equivalent of farm subsidies, and farm corporations could pay the stipends of some students whom they would later hire.

DHPA graduates would be proficient in many if not all phases of crop management (and/or livestock), although a limited degree of specialization could be possible as dictated by the residency program. Geographical areas and horticultural vs. field crops could result in diversity that would be flexible if a very large farm had a staff of several DHPAs. There could be DHPA horticulturists, DHPA agronomists, DHPA economists, and DHPA agricultural engineers.

Some researchers and farmers are already able to achieve yields two and three times the national average for some crops through precision management. Trends toward high technology and bioengineering will magnify such efforts with laboratory and data systems support. Philosophies concerning management practices needed to achieve high production levels have been outlined (Wallace, 1989; Wallace and Wallace, 1990). It is these high production levels that will be orchestrated by the DHPAs.

More intensive and high-precision management, including reduction in postharvest crop losses, is the only way to obtain safer and more productive agriculture that simultaneously has no adverse environmental effects and will still be profitable. If highprecision crop production can be obtained with the help of professional graduates, much land can be freed for trees and other greenbelt materials. Students from professional agricultural schools would also be an important ingredient necessary for reaching national environmental goals.

The United States currently spends $\approx 11 \%$ of its income for food. Since most of the world spends proportionally much more of its income for food than does the United States, i.e., $25 \%$ to $50 \%$, there perhaps would be no severe problem if food costs rose in the United States to provide more and better food (it already is good) on fewer hectares with precise management. It would then be possible to give perhaps one-third of the present farmland, much of which may be marginal, back to greenbelts for a better environment. The skilled management needed for high-precision agriculture could come, in part, from a new kind of Professional Agricultural School.

\section{Literature Cited}

Wallace, A. 1989. The interacting nature of limiting factors on crop production: Implications for biotechnology. Soil Sci. 147:469-473.

Wallace, A. and G.A. Wallace. 1990. Special issue on interactions of limiting factors in crop production. J. Plant Nutr. 13:309-466. 